\title{
Barriers and Strategies for Improving Medication Adherence Among People Living With COPD: A Systematic Review
}

\author{
Bimbishar Bhattarai, Ramesh Walpola, Amary Mey, Shailendra Anoopkumar-Dukie, and \\ Sohil Khan
}

\begin{abstract}
BACKGROUND: While medication is an integral component of the effective management of COPD, contemporary studies report that more than half of all people who are prescribed medication for the management of their COPD do not adhere to therapy. Enhancing medication adherence and improving health outcomes for those living with COPD are among the key challenges for the global health community. This systematic review aims to identify the rate of nonadherence among people who are prescribed controller medication for the management of their COPD, and identifies the barriers and facilitators that influence their medication use behavior. METHODS: A systematic search of medical databases (ie, MEDLINE, CINHAL, and EMBASE) was conducted using key words to identify literature in the English language, published between January 2003 and December 2019. Included studies were assessed for quality using the Strengthening the Reporting of Observational Studies in Epidemiology (STROBE) checklist. RESULTS: A total of 1,474 studies were identified from the initial database search, of which 38 met the inclusion criteria. Of these 38 studies, 37 reported on rates of nonadherence (ranging from $22 \%$ to $93 \%$ ), 30 reported on barriers to adherence, 24 reported on enablers to adherence, and 16 reported on both. The majority (33) of the studies were conducted in high-income nations. The quality of articles ranged from $47 \%$ to $90 \%$. Medication-taking behavior was reported to be influenced by several factors such as subjects' beliefs about medication, their experiences of and satisfaction with medication effectiveness, their concerns regarding medication side effects, their personal circumstances, habits and health status, and their relationships with health care providers. CONCLUSIONS: Adherence to COPD medication was generally low, with the majority of studies identifying the presence of depression and subjects' concern about the harmful effects of the medicine as barriers to adherence. Variability exists on the reported rates of nonadherence, possibly due to different measures utilized to assess adherence. Future research in low-income nations is needed. Key words: medication adherence; nonadherence; inhaler devices; chronic obstructive pulmonary disease; COPD. [Respir Care 2020;65(11):1738-1750. (C) 2020 Daedalus Enterprises]
\end{abstract}

\section{Introduction}

Medication adherence is an integral part of chronic disease management, and it has been defined by the World Health Organization (WHO) as "the extent to which the

Mr Bhattarai and Drs Mey, Anoopkumar-Dukie, and Khan are affiliated with the School of Pharmacy and Pharmacology, Quality Use of Medicines Network, Menzies Health Institute Queensland, Griffith University, Gold Coast, Australia. Dr Walpola is affiliated with School of Public Health and Community Medicine, The University of New South Wales, Sydney, Australia. Dr Khan is affiliated with the Mater Research Institute, The University of Queensland, South Brisbane, Australia and person's behavior corresponds with the agreed recommendations from a health care provider." ${ }^{1}$ Vrijens et $\mathrm{al}^{2}$ divided adherence into 3 components: initiation, implementation, and discontinuation. Initiation is the first step, when patients take their first prescribed dose of medication, followed by implementation where patients take the actual dose, and finally discontinuation, where

also affiliated with the Manipal College of Pharmaceutical Sciences and Prasanna School of Public Health, Manipal Academy of Higher Education, Manipal, India.

The authors have disclosed no conflicts of interest. 


\section{Medication AdHERENCE IN COPD}

patients stop taking medication. In developed countries, almost half of the patients with long-term pharmacotherapy are not adherent. ${ }^{1}$ Studies have suggested that around only half of the individuals with COPD are adherent to their prescribed therapy. ${ }^{3-5}$

COPD is a common disease that, if not managed appropriately, causes an enormous strain on health services. According to the Global Initiative for Chronic Obstructive Lung Disease (GOLD), COPD is a common, preventable, and treatable disease that is characterized by persistent respiratory symptoms and airway limitation. ${ }^{6}$ Common persistent symptoms include dyspnea, chronic cough, and sputum production. An update by the Global Burden of Disease in 2015 estimated that about 174 million people have COPD worldwide. ${ }^{7}$ By 2030, COPD is projected to become the third leading cause of death globally. ${ }^{8}$ In COPD patients, quality of life is impaired, leading to substantial limitations to their regular activity. ${ }^{9}$ When not managed appropriately, COPD can result in complications that may lead to increased health care costs and a burden on the health care system. ${ }^{10}$ For example, in 2004, a retrospective study conducted in the United States reported that patients with COPD utilized more health care services at a cost of $\$ 20,500$ above a comparison cohort. ${ }^{11}$ As such, appropriate disease management can lead to savings in health care and hospitalization costs, along with a reduction in the rate of hospitalization. ${ }^{12}$

Optimal medication adherence in patients with COPD assists in improving disease management and reducing health care costs. ${ }^{13}$ Patients who adhere to treatment have a lower risk of exacerbating their medical condition as compared to those with poor adherence. ${ }^{14} \mathrm{~A}$ study conducted by Vestbo et $\mathrm{al}^{15}$ reported that those who did not adhere to their recommended treatment were twice as likely to be hospitalized when compared with adherent subjects. Medication adherence is a critical component for effective management of COPD and the key to tackling the everincreasing burden of illness. ${ }^{16}$ Conversely, poor adherence is wasteful in terms of resources and negatively affects health, resulting in higher health care costs. ${ }^{17}$ Therefore, understanding what can help people adhere to their recommended medication regimen and what hinders them from taking their medications as prescribed is crucial to developing strategies that help people living with COPD adhere to

Supplementary material related to this paper is available at http://www. rcjournal.com.

Correspondence: Bimbishar Bhattarai MPharm, School of Pharmacy and Pharmacology, Quality Use of Medicines Network, Menzies Health Institute Queensland, Griffith University, Parklands Dr, Southport, Queensland 4222, Australia. E-mail: bimbishar.bhattarai@griffithuni.edu.au.

DOI: $10.4187 /$ respcare.07355 their medications and subsequently optimize their health outcomes.

In the last decade, several systematic reviews have summarized findings from primary research that investigated the interplay between aspects of COPD management and outcomes. ${ }^{12,18-22}$ For example, 3 reviews focused on economic and clinical outcomes of adherence $^{12,18,19} ; 3$ others respectively examined strategies to improve medication adherence,$^{20}$ factors related to the incorrect use of inhalers, ${ }^{21}$ and outcomes of adherence for COPD medication, ${ }^{22}$ while yet another review focused on the relationship between medication adherence and health-related quality of life. ${ }^{23}$ Some of the reviews have established the relationship between adherence, cost, and quality of life. Challenges for appropriate use of medicine and approaches to enhance medication adherence were also analyzed. However, barriers to and enablers of medication adherence were not adequately reported. Additionally, unifying concepts regarding challenges to and facilitators of adherence and the prevalence of adherence in different countries and regions do not appear in these studies. Considering the various hindrances to medication adherence, identifying those factors and developing strategies to improve adherence appear worthwhile. Moreover, the interconnection of barriers to and facilitators of medication adherence necessitates a joint examination of both of these elements within the same review.

Thus, this review aims to evaluate the barriers to and facilitators of medication adherence in subjects with COPD, and specifically to identify the knowledge gaps from the literature. Considering the prevalence of medication nonadherence worldwide, this review also aims to identify the rates of nonadherence to COPD controller medication.

\section{Methods}

\section{Search Strategy}

The Preferred Reporting Items for Systematic Reviews and Meta-Analyses (PRISMA) statement was followed in conducting this systematic review. ${ }^{24}$ The electronic databases MEDLINE, CINAHL, and EMBASE were used to conduct searches. Due to the extensive coverage of journal articles in the fields of nursing, health, and medical sciences, these 3 databases were chosen. Articles published in the English language and human studies from January 2003 to December 2019 were retrieved for analysis. In the first GOLD report, published in 2001, it was anticipated that it could take up to $2 \mathrm{y}$ for the initial recommendations to be implemented. Therefore, in accordance with the GOLD guideline of commencing a review 2 $y$ after publication of the initial report, we conducted this 


\section{Medication AdHERENCE IN COPD}

review with articles published from 2003, collecting the best evidence from extensive literature over the past $16 \mathrm{y}$.

The search was performed using key words and proximity search: (medicat* OR drug*) N3 ("chronic obstructive pulmonary disease" OR "chronic obstructive airway disease" OR "emphysema" OR "chronic bronchitis" OR "COPD") AND (adhere* OR compliance OR persist* OR nonadhere* OR noncompli* OR nonpersist* OR nonadhere* OR noncompli* OR nonpersist*). "N3" is the proximity term for the EBSCOhost searches (ie, MEDLINE and CINAHL), and "NEAR/3" was used for the Embase search. Truncation $(*)$ was used to search for a term and several spellings of that term.

\section{Study Selection}

Primary observational studies conducted on subjects with COPD or health care professionals with a focus on barriers to or facilitators of medication adherence were included. Studies that identified health care professionals' perspectives on medication adherence on subjects with COPD were also included. Here, medication adherence refers to "the extent to which the person's behavior corresponds with the agreed recommendations from a health care provider." Papers without a focus on medication adherence and only examining adherence to pulmonary rehabilitation, oxygen therapy, exercise, and self-management programs were excluded. Studies that did not differentiate between asthma and COPD in their results were also excluded.

Eligible studies included participants of any age or sex with a diagnosis of COPD (regardless of other comorbid conditions) or health care professionals involved in the management of COPD. Initially, titles and abstracts were screened by a single investigator (BB) based on the inclusion criteria. Studies that did not meet the inclusion criteria were excluded by verifying titles and abstracts. Remaining studies that met the inclusion criteria were verified by 2 authors (BB, SK). Any discrepancies were reviewed by other authors (AM, RW). To identify additional relevant literature, a manual search was conducted.

\section{Data Items}

Details retrieved from the articles included study design, population characteristics (eg, sample size, age), the classification of nations based on economy, method to assess adherence, definition of nonadherence, rates of nonadherence, type of therapies used, time since therapy initiation, method to assess barriers and facilitators, barriers to medication adherence, facilitators of medication adherence, and study findings.

\section{Quality Assessment of Included Studies}

The Strengthening the Reporting of Observational Studies in Epidemiology (STROBE) checklist for cohort, case-control, and cross-sectional studies was used for assessing the quality of the included studies. ${ }^{25}$ The 22 point STROBE checklist was used to score these studies by calculating "yes" answers compared to the result of "yes + no" answers, whereas "not applicable" had no relation with the results. Therefore, the percentage score was calculated as: $\{[$ yes/(yes + no $)] \times 100\}$. The result of each study was summarized as a percentage and ranked. Quality assessment was independently evaluated by 2 authors (BB, SK), and any disagreements were resolved by the third author (RW). Details about quality assessment are reported in the supplementary materials (see the supplementary materials at http://www.rcjournal.com).

\section{Results}

\section{Search Results}

The initial database and manual search identified 996 results after removing duplicates. Excluding records by title and abstract and assessing for eligibility criteria yielded 38 relevant papers to be included in this study. Further details about the results included in this review are shown in Figure 1.

\section{Study Characteristics}

Details about the study features are reported in Table 1 and the supplementary materials (see the supplementary materials at http://www.rcjournal.com). The articles in this systematic review include studies from 24 countries. The majority of the studies were conducted in Europe (no. = 17), ${ }^{3,26-41}$ followed by North America (no. = 13), ${ }^{13,29,42-51}$ Asia (no. = 8), ${ }^{29,52-58}$ Australia (no. = 2) ${ }^{59,60}$ Africa (no. = 1) ${ }^{61}$ and South America $($ no. $=1) .^{29}$ Among the 38 studies reviewed, 2 were conducted in multiple countries, ${ }^{29,37}$ and 1 study was conducted in 2 countries of Asia. ${ }^{54}$ The total of the study populations was 343,689 , and the mean age of the participants was $66.94 \mathrm{y}$. Thirty-seven studies were conducted with patients, whereas one of the studies assessed perspectives of both patients and health care professionals. ${ }^{49}$ The majority of the studies had a cross-sectional design (no. $=20$ ), and the remainder were cohort studies (no. $=18$ ). Of the 38 articles reviewed, 37 studies were conducted using quantitative methods, whereas 1 study applied both quantitative and qualitative methodologies. Thirty-one studies in this review were conducted in high-income nations; 4 studies were conducted in high/uppermiddle-income nations, 2 studies in lower-middle-income nations, and 1 study in a low-income nation. 


\section{Medication AdHERENCE IN COPD}

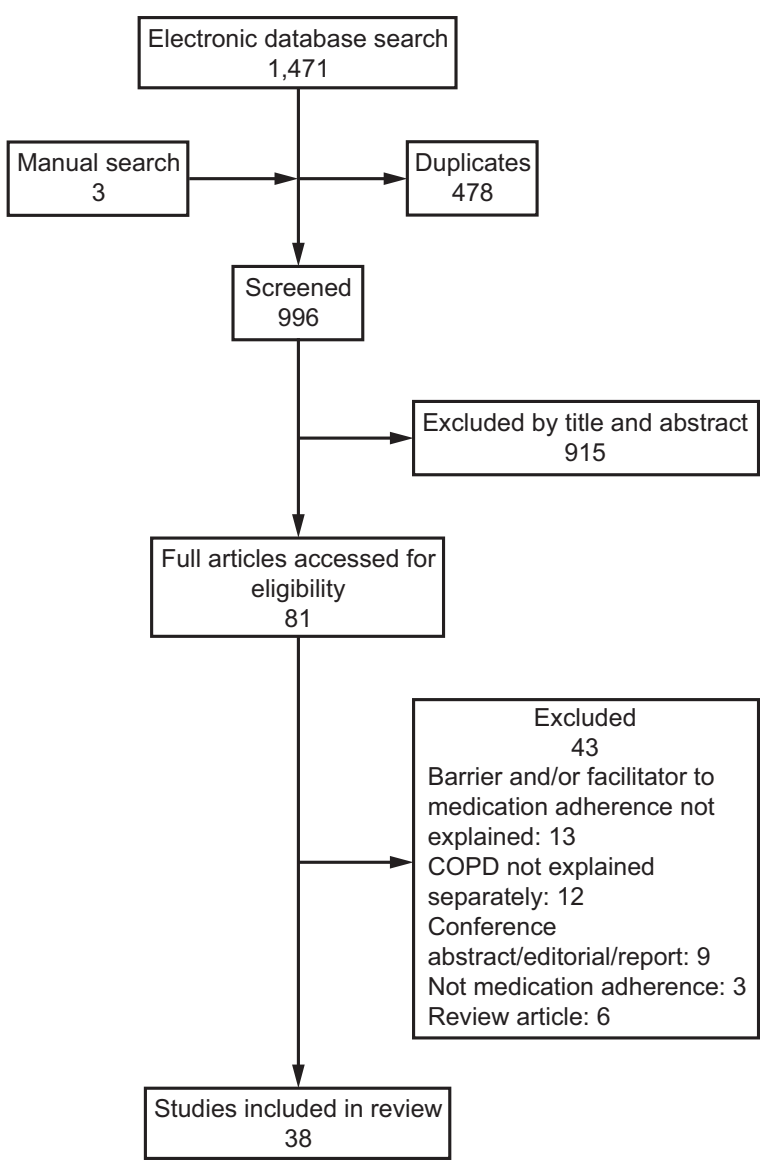

Fig. 1. Flow chart.

\section{Methodological Quality}

The STROBE checklist for the quality of articles ranged from $46.67 \%{ }^{61}$ to $90 \% .{ }^{46}$ All the studies met the criteria for describing the abstract, background, objectives, and setting. Seven studies performed sensitivity analyses to measure the robustness of the statistical methods used. ${ }^{28,38,40,41,43,45,57}$ Furthermore, only 6 studies clarified the results of included subjects with a flow diagram..$^{31,33,38,40-42}$ Among the included studies, 8 studies noted potential sources of bias. ${ }^{28,35,42,47,52,55,59,60}$ The majority of the studies used self-reporting assessment measures, while the reporting bias of the subjects was presented in 5 studies. $^{28,47,55,59,60}$ One of the studies reported both selection bias and recall bias among subjects, ${ }^{55}$ and another study considered the selection bias in the use of the periodic instrument for the subject. ${ }^{52}$

\section{Prevalence of Nonadherence and Type of Therapies}

Thirty-seven studies reported rates of nonadherence. The reported rates and the definition of nonadherence in subjects with COPD are shown in Table 1 . Nonadherence rates ranged from $22 \%{ }^{27}$ to $93 \% .{ }^{61}$ More than half of the studies stated nonadherence in $>50 \%$ of the subjects. Thirty-seven of the 38 studies assessed the rates of nonadherence at one time only due to the study design. However, in 1 longitudinal study, nonadherence was measured at baseline, after 3 months, and after 12 months. ${ }^{28}$ In this study, although the number of subjects decreased at each time point after the baseline measurement, the subjects adherent to their medication was increased at 3 months and at 12 months. There was little difference between the rates of nonadherence between the economic levels of the countries. For example, studies conducted in low-income (Nepal) and lower-middle-income (Vietnam) countries have nonadherence rates of $65 \%$ and $70 \%$, respectively, which is similar to the findings from high-income countries like Australia $(63 \%)$ and Germany $(66.2 \%)$. $^{28,53,55,59}$ Self-report (no. $=18$ ) and pharmacy claims data $($ no. $=18)$ were equally used to assess adherence, followed by electronic monitoring (no. = 1 ); one study did not assess adherence. ${ }^{57}$ Several scales without specific names (no. $=6)^{36,37,49,54,56,61}$ were the most frequently used self-report measure followed by the Medication Adherence Report Scale (no. = 4), ${ }^{28,47,59,60}$ the 8-item Morisky Medication Adherence Scale (no. = 3), ${ }^{49,54,61}$ the 4item Morisky Medication Adherence Scale (no. = 2), ${ }^{3,58}$ the Morisky Scale (no. $=1$ ) ${ }^{26}$ the Measure of Treatment Adherence Scale (no. $=1$ ), ${ }^{30}$ and the Test of Adherence to Inhaler Scale (no. $=1$ )..$^{55}$

In 12 studies, ${ }^{13,27,32,34,36,38,39,41-43,51,60}$ subjects were using either monotherapy (long-acting $\beta_{2}$ agonist [LABA], longacting muscarinic antagonist [LAMA], or inhaled corticosteroid [ICS]) or dual therapy (ICS/LABA or LABA/LAMA); in 3 studies, subjects were using either monotherapy, dual therapy, or triple therapy (ie, ICS/LABA/LAMA), ${ }^{31,45,54}$ and in 1 study subjects were using only triple therapy. ${ }^{50}$ Two studies reported that subjects were using only monotherapy (ie, LABA or LAMA ${ }^{35,57}$ and another study reported that subjects were using only dual therapy (ie, ICS/LABA). ${ }^{33}$ The other 19 studies did not mention the types of therapies that subjects were using. Among the 19 studies that reported the type of inhaled therapy (ie, monotherapy, dual therapy, or triple therapy) used by subjects, 7 studies examined the difference in the rates of nonadherence based on the therapies used. ${ }^{27,32,38,39,43-45}$ Four studies noted that subjects had higher adherence to LAMA (tiotropium) than LABA, ICS, or ICS/LABA, ${ }^{27,32,38,39}$ and 2 studies reported that subjects had higher adherence to LABA than LAMA or ICS. ${ }^{43,44}$ Subjects from 12 of the 38 studies were using their COPD medication for $\geq 12$ months ${ }^{29,31,33,34,36,41,43,44,49,50,52,60}$; in 3 studies subjects were using their COPD medication for $<12$ months, ${ }^{35,48,51}$ and 2 studies had both newly prescribed (ie, medicine users for $<$ 12 months) and prevalent users as subjects (medicine user for $\geq 12$ months). ${ }^{32,57}$ 


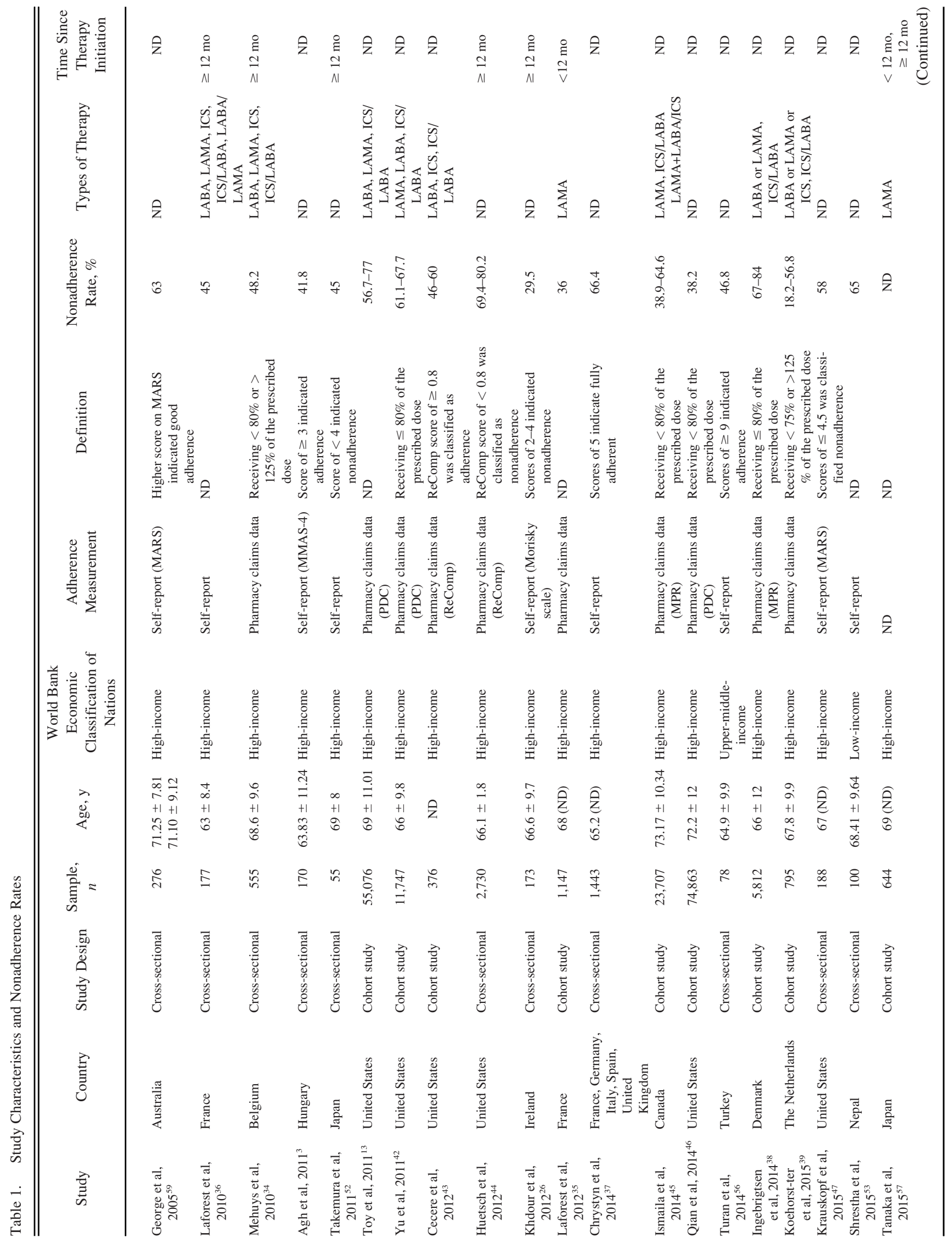




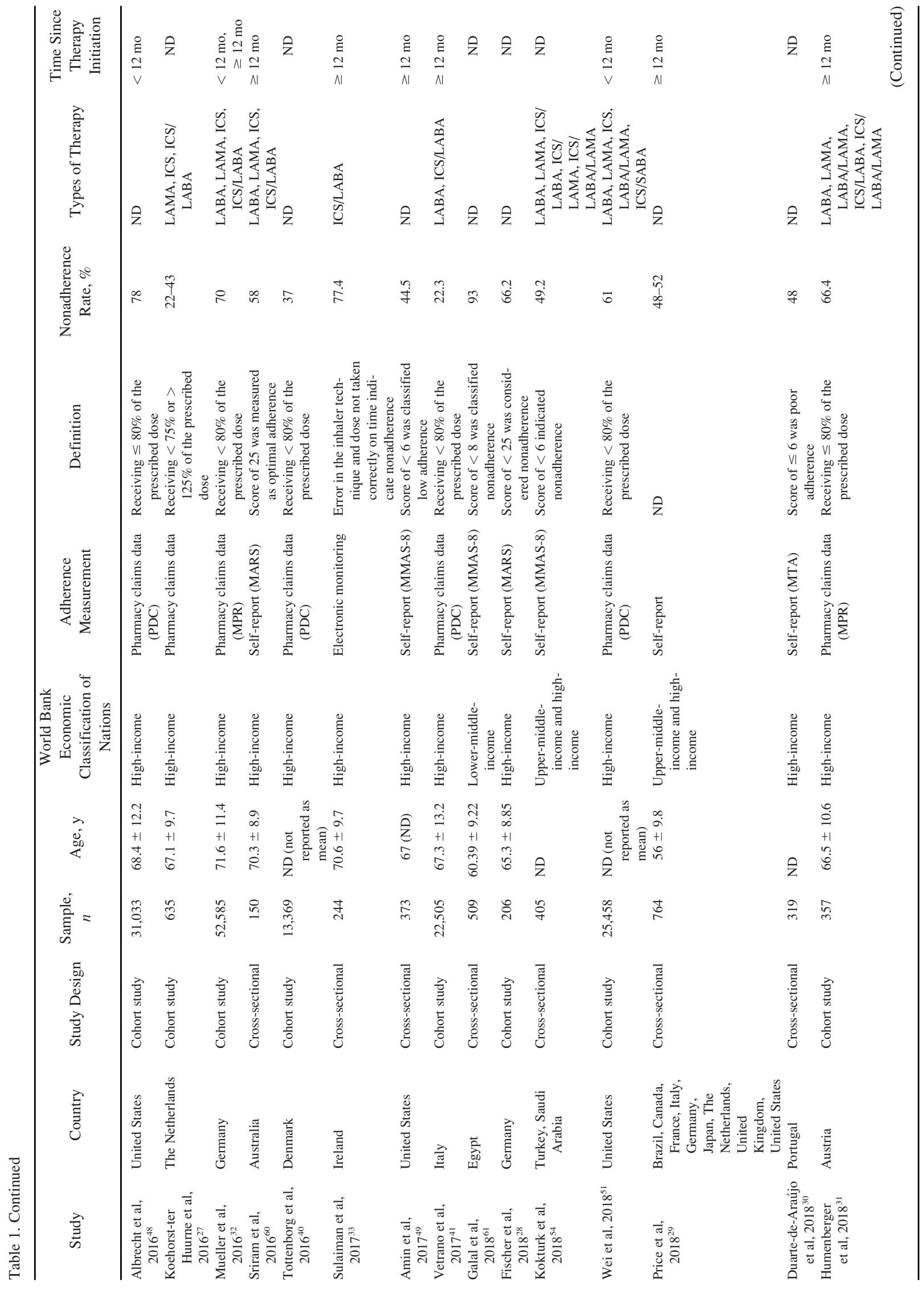




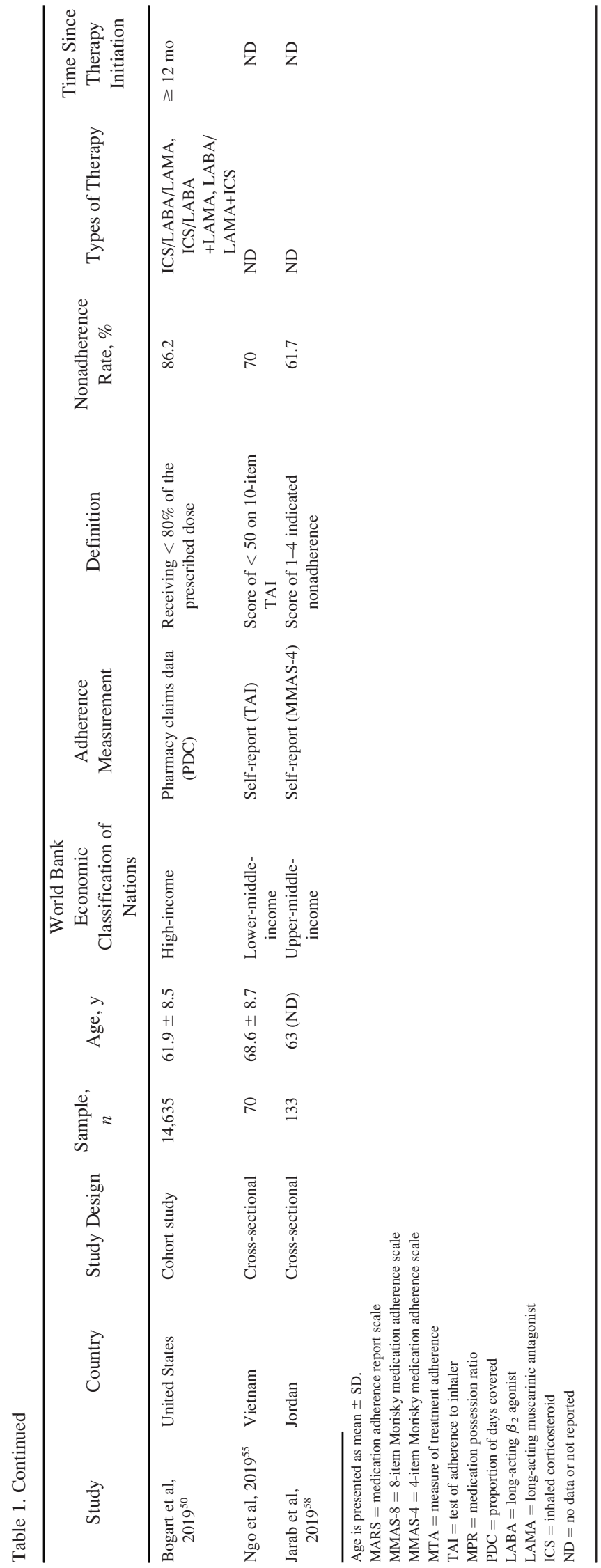

\section{Barriers to Medication Adherence}

Of the 38 included studies, 30 listed issues that hindered

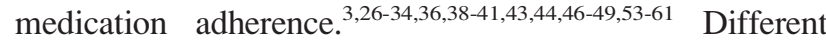
methods were used to assess barriers to and facilitators of medication adherence. For example, 23 studies used regression analyses, ${ }^{13,27,28,31,32,35,37-41,43-49,51,54,55,57,58} 6$ studies used both regression analyses and questionnaires, ${ }^{3,26,36,52,59,61} 3$ studies used questionnaires only ${ }^{29,53,56}$; separate studies used inhaler technique evaluation and regression analyses,${ }^{34}$ assessment of acoustic recordings and regression analyses, ${ }^{33}$ inhaler technique evaluation, ${ }^{60}$ and interviews and regression analyses. ${ }^{30}$ Additionally, 2 studies compared the differences between adherence rates of different drugs. ${ }^{42,50}$

Regarding barriers to adherence, the presence of depression was identified as one of the potential barriers to adherence. ${ }^{26,36,44,46,48,54,56,58}$ Concern about the side effects or harmful effects of medicines was reported in 7 studies associated with lower treatment adherence, ${ }^{3,28,47,53,57,58,61}$ followed by smoking (no. $=5)^{3,30,43,56,57}$ forgetfulness (no. $=4$ ), ${ }^{3,26,36,53}$ presence of comorbid conditions (no. $=4$ ),,$^{26,32,41,58}$ and polypharmacy (no. $=3$ ) ${ }^{36,41,53}$ Poor inhaler technique was stated as the cause of suboptimal adherence in 2 of the studies. ${ }^{34,60}$ Amin and colleagues ${ }^{49}$ reported poor adherence among subjects who had a low level of confidence in using their inhaler devices. One study associated reduced quality of life with nonadherence, ${ }^{54}$ whereas another study reported that a better quality of life was linked with nonadherence. ${ }^{3}$

One of the included studies identified dissatisfaction with the treating physician and limited interaction between clinician and patient as the cause of nonadherence. ${ }^{59}$ Several studies reported that severity of the disease was the barrier to medication adherence. 29,31,33,55 For example, Price and colleagues ${ }^{29}$ reported that younger subjects with less disease severity were less likely to take medicine. Similarly, Humenberger et $\mathrm{al}^{31}$ stated that subjects with mild disease severity were less likely to adhere to their recommended therapy, whereas a study conducted in Vietnam reported that subjects with frequent exacerbations and greater disease severity had suboptimal adherence. ${ }^{55}$ Sulaiman and colleagues ${ }^{33}$ reported that damage in lung function and decline in cognitive status were barriers to adherence. Koehorst-ter Huurne and colleagues ${ }^{27,39}$ concluded that underuse and overuse of inhaler device were associated with higher $\mathrm{FEV}_{1}$ and lower $\mathrm{FEV}_{1}$ at baseline, respectively.

\section{Facilitators of Medication Adherence}

Among the 38 included studies, 24 studies reported enablers to medication adherence among subjects with COPD. ${ }^{3,13,26,28-31,34-39,41-45,50-52,54,57,59}$ Four of these studies highlighted that the patient's belief in the medication is an 


\section{Medication AdHERENCE IN COPD}

essential factor to enhance medication adherence. ${ }^{26,28,30,59}$ Subjects had greater adherence when they had a better understanding of their disease and drug therapy. ${ }^{36,59}$ Two studies reported that subjects' confidence in health care professionals' expertise was a facilitator to medication adherence. $^{43,59}$ In addition, several studies concluded that using fewer inhaler devices and reducing the dosing regimen was associated with higher adherence. ${ }^{13,39,42,50}$ Five studies identified that adherence was enhanced in subjects with greater disease severity..$^{30,31,38,41,44}$ One study independently identified repeated instruction in the use of inhaler devices as reducing nonadherence, ${ }^{52}$ while another study noted that training for inhaler use and inhaler technique checks were responsible for overcoming nonadherence. $^{29}$ Two studies reported that elderly subjects had higher adherence, ${ }^{3,34}$ while another study reported that higher education and older age ( $\geq 60 \mathrm{y}$ ) were linked with better treatment adherence. ${ }^{54}$ Chrystyn et al $^{37}$ revealed that better quality of life, less frequent exacerbations, and patient satisfaction with their inhaler device are linked with better adherence. Fourteen studies did not discuss enablers to adherence. ${ }^{27,32,33,40,46-49,53,55,56,58,60,61}$

\section{Discussion}

This review has provided insight into barriers to medication adherence and strategies to improve adherence among subjects with COPD through peer-reviewed studies. Variations in the rates of medication nonadherence (22$93 \%$ ) were identified in subjects from 24 countries. Although only 3 studies from low-income and lower-middle-income countries were included, there was not a significant difference between nonadherence rates from these countries and nonadherence rates in studies conducted in high-income countries. ${ }^{28,31,53,55,59}$ This review has identified a number of factors that result in nonadherence: depression, comorbid conditions, concerns about medication, forgetfulness, reduced as well as better quality of life, smoking, choice of medicines, limited patient-clinician interaction, and incorrect use of inhaler devices. Another review reported that the cost of medicines was also a factor for nonadherence among COPD subjects. ${ }^{62}$ Although cost may be a barrier to adherence, none of the studies included in this review considered cost as a major barrier. Cost-related nonadherence is one of the major problems in both highincome and low-income countries. ${ }^{63,64} \mathrm{~A}$ multi-country study conducted in high-income nations revealed that costrelated nonadherence is higher in low-income subjects. ${ }^{63}$ Even in low-income nations, cost-related nonadherence among individuals with chronic disease is higher in lowincome subjects than high-income subjects. ${ }^{64}$ Cost as a barrier to medication adherence may vary depending upon the income level of the subjects and the country's universal drug coverage policy. ${ }^{63-65}$ In particular, low-income subjects have poor adherence.

Several methods were used to assess nonadherence in the included studies. This could be due to the unavailability of accepted measures to assess rates of nonadherence. Among the instruments used, there were discrepancies in the definition and measurement criteria of nonadherence, which may influence the rate reported. Moreover, other measures that were used, such as pharmacy claims data and electronic measures, have different measurement criteria of nonadherence than self-reported measures. This may also lead to variances in the rates of nonadherence. Even if studies used the same method to assess adherence (eg, pharmacy claims data, ${ }^{27,32}$ the 8-item Morisky Medication Adherence Scale, ${ }^{54,61}$ and the 4-item Morisky Medication Adherence Scale, ${ }^{3,58}$ we noted variations in cutoff values to define nonadherence. The use of different measures to evaluate adherence could yield varying results. Another reason for the variance in rates of nonadherence may be differences in patients' beliefs regarding effectiveness of or concern about their medication. ${ }^{26,28,30,47,53}$ In chronic illness, the patient's belief is one of the important predictors for differences in adherence. ${ }^{66}$ In this review, individual belief may have varied among the included studies and may have resulted in a difference in rates of nonadherence.

Optimal medication adherence can be attained when subjects have positive beliefs about their medication; conversely, adherence is reduced when subjects have concerns about their medication. ${ }^{26,28,30,47,53,57,58,61}$ This review revealed that subjects were more likely to be adherent if they had greater belief about the medication's effectiveness. ${ }^{26,28,59}$ On the one hand, when thoughts about a medication are dominated by side effects and fear of unusual side effects, subjects are more likely to discontinue their medication. ${ }^{67,68}$ For example, due to the side effects of ICS, almost half of the Americans low-income minority patients were nonadherent. ${ }^{69}$ On the other hand, optimal adherence is related to patients' perceived treatment benefits and confidence in their treatment management. ${ }^{70,71}$ Medication adherence is increased in patients who have a specific belief about the necessity of COPD medicines and their feeling toward medication effectiveness. ${ }^{28,72}$ If the subjects felt their medicine was effective, then they were more likely to adhere to it. ${ }^{26,30,59}$ This finding is consistent with a study conducted in different European countries where subjects' satisfaction with the use of their inhaler devices was one of the key attributes for treatment adherence. ${ }^{37,73}$ In fact, subjects observed both benefits and ill effects of medicines depending on whether they accepted and understood the necessity of their medicines. ${ }^{69}$ These beliefs, which subjects experience in their everyday life regarding medicine, are complex and crucial determinants of self-management behaviors. Therefore, it may be essential to focus on these underlying beliefs to 


\section{Medication AdHERENCE IN COPD}

improve medication adherence. Although patients' beliefs about their medication is an important factor of adherence, none of the studies from low-income or lower-middle-income nations have reported evaluating subjects' beliefs as a factor of their adherence. This may be an issue in low-income and lower-middle-income nations, and this knowledge gap about patients' beliefs and the association with medication adherence in literature should be addressed.

Studies revealed that the use of multiple respiratory inhalers is more strongly associated with suboptimal adherence than treatment with a single inhaler device, which may be due to challenges related to having multiple inhaler devices. ${ }^{42,74}$ In this review, use of a single inhaler device was associated with better adherence. ${ }^{42,50}$ Notably, the majority of the studies did not report a correlation between nonadherence and therapies used by subjects. ${ }^{3,26,28-30,35-37,40,41,44,46-51,55-59}$ Studies indicated that subjects on monotherapy with LAMA had better adherence than those treated with LABA, ICS, or ICS/LABA. ${ }^{27,32,38,39}$ In subjects with asthma, better adherence was observed in those who were using dual therapy (ie, ICS/LABA) than in those using ICS alone, which may be due to the increased benefit of the medicine and better symptom control with combination therapy. ${ }^{75}$ This review could not establish any relationship between treatment adherence and subjects initiating therapy because more than half of the included studies did not report the time since therapy was initiated. A limitation among the reviewed articles is that, even though the majority of subjects in half of the studies were using their medication for $>12$ months, the data were still inadequate to compare adherence of newly prescribed medicine users with the adherence of prevalent users. However, a recent study conducted among statin users reported that subjects adherent to statin medicine dropped from $54 \%$ at 6 months to $30.7 \%$ at $9 \mathrm{y}^{76}$ The lack of studies reporting on the differences between adherence to treatment among monotherapy, dual therapy, and triple therapy in newly prescribed and long-time COPD medicine users might be an important opportunity for researchers and health care professionals to consider in the near future.

This review has identified a number of factors that have reduced treatment adherence in subjects with COPD. The finding of one previous study suggested that subjects with a better quality of life were associated with poor treatment adherence. ${ }^{5}$ Another review noted that when the quality of life is enhanced, it may result in nonadherence ${ }^{18}$; however, good adherence is associated with improved quality of life. ${ }^{19}$ Our results indicate that the correlation between medication adherence and quality of life may be ambivalent. Our review supports that a better quality of life is not only related to optimal adherence, but poor adherence also leads to reduced quality of life. Conversely, better adherence might result in an improved quality of life. ${ }^{23,52}$ Quality of life and adherence may have a dual relationship, and both of these elements may affect each other. Furthermore, the presence of comorbidities such as cardiovascular disease, depression, anxiety, and musculoskeletal disease in patients with COPD reduce the quality of life. ${ }^{77}$ Depression also reduces the quality of life, and medication adherence and quality of life can be linked because $>40 \%$ of patients with COPD have depression. ${ }^{78,79}$ This review supports the finding of a previous review that depression results in lower health status and is connected with reduced adherence among subjects with COPD. ${ }^{80}$ Cognitive function in subjects with COPD could be affected by depressive and anxiety symptoms, which may, in due course, affect treatment adherence. ${ }^{56} \mathrm{~A}$ study conducted by Bosley et $\mathrm{al}^{81}$ observed a relationship between adherence and psychological factors associated with nebulized therapy. The authors identified that depressed people negatively observe their condition and report that an increased disability causes a depressed mood. ${ }^{81}$ Both respiratory disability and depression may interact and exacerbate each other leading to increased patient discomfort.

Although studies have reported that greater disease severity is associated with suboptimal adherence, this was not established in all studies. ${ }^{33,55}$ In some of the studies, there was an inverse association between treatment adherence and higher disease severities. ${ }^{38,41,44}$ This inverse association might be explained by the fact that continuous medication is required for patients to treat their disease severity. Furthermore, in one of the former studies, subjects had impaired cognitive status resulting in poor adherence, and the relatively small sample size $(N=70)$ of another study means that the results might not be generalizable.

In this review, smokers were less likely to adhere to their medication than nonsmokers. ${ }^{3,30,43,56,57}$ This finding supports previous research which suggests that smoking results in suboptimal use of medication among subjects with COPD. ${ }^{82,83}$ Inhaled corticosteroids which are one of the most commonly prescribed medicines for patients with COPD, are less effective in smokers, leading to a reduced therapeutic effect. ${ }^{82,84}$ This may be one of the reasons why smokers may not refill their prescriptions, thus leading to suboptimal medication adherence. Another reason may be that smokers spend more on tobacco products, which may be the cause of a cash deficit to buy their medication. ${ }^{82}$ Although smoking results in suboptimal adherence, only 5 of the studies in this review highlighted the effect of smoking on adherence. Smoking is also one of the leading causes of COPD, yet the role of health care professionals to raise awareness in COPD subjects to cease smoking was not a focus in the reviewed articles. This represents another area that needs further study. 


\section{MedicAtion AdHERENCE IN COPD}

In other chronic diseases, optimal adherence to the therapeutic regimen was enhanced with successful patient-clinician interaction. ${ }^{85,86}$ However, in this review, subjects were nonadherent when their physicians provided less time and limited information about the illness. ${ }^{59}$ Subjects who have less understanding of their disease management exhibited suboptimal adherence as well as low satisfaction and belief in their treating physician. In contrast, subjects with a better understanding of their disease and drug therapy and greater confidence in their treating physician demonstrated better adherence. ${ }^{36,43,59}$ The literature suggests that education can provide various benefits and ameliorate the health trajectory of patients. ${ }^{87}$ Educating subjects is crucial because it helps them understand their disease and the benefits and proper use of medication.

Appropriate use of the inhaler devices by patients is an essential predictor of medication adherence and is the cornerstone of COPD therapy. Previous studies have reported that $4-94 \%$ of subjects demonstrate incorrect use of inhaler devices, ${ }^{21,62,88}$ depending upon the method of assessment and type of inhaler device used. To minimize the suboptimal use of inhaler devices, device use education is an influential factor in enhancing adherence. A review by Lareau and Hodder ${ }^{89}$ highlighting the use of inhaler devices explained that patients should be informed about an inhaler's indication and frequency of use, should be asked to demonstrate the use of the device, and should be made aware of the importance of training in inhaler techniques. Interestingly, our results indicate that greater confidence in subjects' ability to use inhaler devices helps improve medication adherence. ${ }^{49}$ It is important to consider that the inhaler devices should be easy to use, have minimal steps to operate, and have a breath-actuated mechanism. ${ }^{90}$ Despite the ease of use of the inhaler devices, 2 articles in this review highlighted that adherence to inhaled medication also depends upon the specific class of medication, because subjects use the medication class that provides them better relief. ${ }^{27,44}$ Therefore, it is critical to contemplate that adherence to one type of medication class does not necessarily mean subjects may be adherent to another type of medication. Further studies are required to fully understand the connection between the class of medication and adherence.

This review has identified several knowledge gaps among the articles reviewed. The majority of the studies were conducted in high-income countries; only 3 studies were from lower-middle-income and low-income countries. This is paradoxical because $>90 \%$ of COPD deaths occur in low-income and middle-income countries. ${ }^{91}$ Unfortunately, there are limited studies to understand factors associated with medication adherence in these countries. This shows a geographical knowledge gap among the included studies with a scarcity of literature from low-income countries. Further research from these countries is warranted.

Health care professionals are key players in the management of disease, and their understanding of patients' medication-taking is crucial. However, there are limited studies in understanding the health care professionals' perspectives of their patients' medication adherence. Of the 38 articles included in this review, only 1 study highlighted health care professionals' perspectives regarding patients' medication adherence. ${ }^{49}$ This is an important issue, and consideration should be given to future research among health care professionals because they are the ones who provide healthand medication-related services to patients with COPD. Moreover, conducting research among these groups of the population will help rectify the dearth of information.

All of the included studies identified rates of nonadherence and, with the inclusion of mostly structured questionnaires and with regression analyses, they examined factors associated with medication adherence. One study included a structured questionnaire followed by semistructured interviews to justify participants' opinions. ${ }^{30}$ A limitation among the reviewed studies was the fact that 37 articles did not delve into the subjects' opinions and behaviors to explain precisely why subjects were not taking their medicines as prescribed. Reasons for medication nonadherence and facilitators to medication adherence were based on the answers from closed-ended questions and regression analyses. Due to this style of questionnaire and analyses, the responses from patients, including their thoughts and feelings, were missing. Thus, this review highlights the lack of qualitative studies in assessing barriers to and facilitators of medication adherence. Future research should evaluate the patients' lived experience and medication use behavior through qualitative studies.

A limitation of our review was that we examined 3 databases with peer-reviewed literature published in the English language, which may have led to the exclusion of some articles such as gray literature. However, we included the most relevant and recent articles that met the review criteria. Although the findings from this study are clear with regard to medication adherence, the evidence is mainly generated from observational studies without the inclusion of randomized controlled trials.

\section{Conclusions}

This review highlights factors associated with challenges to and facilitators of medication adherence. Adherence to COPD medication was low with nonadherence rates $>50 \%$ in more than half of the studies. The presence of comorbid conditions such as depression and concern about the harmful effects of the medicine were considered barriers to adherence in the majority of the studies, whereas patients' positive beliefs in the medication were considered 


\section{MedicAtion AdHERENCE IN COPD}

a facilitator to adherence. Variability exists in the reported rates of nonadherence, which may be a result of the type of measures that the studies utilized. This review reveals a lack of qualitative studies to identify factors associated with medication adherence. Currently, there are few studies that discuss health care professionals' perspectives of their patients' medication adherence, thus careful assessment of their views is warranted. Future research design requires evaluation of the patients' lived experiences and medication use behavior through qualitative studies, as well as more focus on low-income nations.

\section{REFERENCES}

1. World Health Organization. Adherence to long-term therapies: evidence for action. Available at: https://www.who.int/chp/knowledge/publications/ adherence_full_report.pdf?ua=1. Accessed March 8, 2019.

2. Vrijens B, De Geest S, Hughes DA, Przemyslaw K, Demonceau J, Ruppar T, et al. A new taxonomy for describing and defining adherence to medications. Br J Clin Pharmacol 2012;73(5):691-705.

3. Agh T, Inotai A, Meszaros A. Factors associated with medication adherence in patients with chronic obstructive pulmonary disease. Respiration 2011;82(4):328-334.

4. de Oca MM, Menezes A, Wehrmeister FC, Varela MVL, Casas A, Ugalde L, et al. Adherence to inhaled therapies of COPD patients from seven Latin American countries: the LASSYC study. PLoS One 2017;12(11):e0186777.

5. Horvat N, Locatelli I, Kos M, Janezõicõ A. Medication adherence and health-related quality of life among patients with chronic obstructive pulmonary disease. Acta Pharm 2018;68(1):117-125.

6. Vogelmeier CF, Criner GJ, Martinez FJ, Anzueto A, Barnes PJ, Bourbeau J, et al. Global strategy for the diagnosis, management, and prevention of chronic obstructive lung disease 2017 report. GOLD executive summary. Am J Respir Crit Care Med 2017;195(5):557-582.

7. Vos T, Allen C, Arora M, Barber RM, Bhutta ZA, Brown A, et al. Global, regional, and national incidence, prevalence, and years lived with disability for 310 diseases and injuries, 1990-2015: a systematic analysis for the Global Burden of Disease Study 2015. Lancet 2016; 388(10053):1545-1602.

8. World Health Organization. Chronic obstructive pulmonary disease (COPD). Available at: http://www.who.int/respiratory/copd/en. Accessed March 4, 2019.

9. Peruzza S, Sergi G, Vianello A, Pisent C, Tiozzo F, Manzan A, et al. Chronic obstructive pulmonary disease (COPD) in elderly subjects: impact on functional status and quality of life. Respir Med 2003;97 (6):612-617.

10. Chapman K, Mannino D, Soriano J, Vermeire P, Buist AS, Thun M, et al. Epidemiology and costs of chronic obstructive pulmonary disease. Eur Respir J 2006;27(1):188-207.

11. Menzin J, Boulanger L, Marton J, Guadagno L, Dastani H, Dirani R, et al. The economic burden of chronic obstructive pulmonary disease (COPD) in a US Medicare population. Respir Med 2008;102(9):12481256.

12. Boland MR, Tsiachristas A, Kruis AL, Chavannes NH, Rutten-van Mölken MP. The health economic impact of disease management programs for COPD: a systematic literature review and meta-analysis. BMC Pulm Med 2013;13:40.

13. Toy EL, Beaulieu NU, McHale JM, Welland TR, Plauschinat CA, Swensen A, et al. Treatment of COPD: relationships between daily dosing frequency, adherence, resource use, and costs. Respir Med 2011;105(3):435-441.
14. Sokol MC, McGuigan KA, Verbrugge RR, Epstein RS. Impact of medication adherence on hospitalization risk and healthcare cost. Med Care 2005;43(6):521-530.

15. Vestbo J, Anderson JA, Calverley P, Celli B, Ferguson GT, Jenkins C, et al. Adherence to inhaled therapy, mortality, and hospital admission in COPD. Thorax 2009;64(11):939-943.

16. Antoniu SA. Adherence to inhaled therapy in COPD: effects on survival and exacerbations. Expert Rev Pharmacoecon Outcomes Res 2010;10(2):115-117.

17. de Miguel-Díez J, Carrasco-Garrido P, Rejas-Gutierrez J, MartínCenteno A, Gobartt-Vázquez E, Hernandez-Barrera V, et al. Inappropriate overuse of inhaled corticosteroids for COPD patients: impact on health costs and health status. Lung 2011;189(3):199-206.

18. Van Boven JFM, Chavannes NH, Van Der Molen T, Rutten-Van Mölken M, Postma MJ, Vegter S. Clinical and economic impact of non-adherence in COPD: a systematic review. Respir Med 2014;108 (1):103-113.

19. Mäkelä MJ, Backer V, Hedegaard M, Larsson K. Adherence to inhaled therapies, health outcomes and costs in patients with asthma and COPD. Respir Med 2013;107(10):1481-1490.

20. Bryant J, McDonald VM, Boyes A, Sanson-Fisher R, Paul C, Melville $\mathrm{J}$. Improving medication adherence in chronic obstructive pulmonary disease: a systematic review. Respir Res 2013;14(1):109.

21. Lavorini F, Magnan A, Dubus JC, Voshaar T, Corbetta L, Broeders $\mathrm{M}$, et al. Effect of incorrect use of dry powder inhalers on management of patients with asthma and COPD. Respir Med 2008;102(4):593-604.

22. Charles MS, Blanchette CM, Silver H, Lavallee D, Dalal AA, Mapel D. Adherence to controller therapy for chronic obstructive pulmonary disease: a review. Curr Med Res Opin 2010;26(10):2421-2429.

23. Ágh T, Dömötör P, Bártfai Z, Inotai A, Fujsz E, Mészáros Á. Relationship between medication adherence and health-related quality of life in subjects with COPD: a systematic review. Respir Care 2015; 60(2):297-303.

24. Moher D, Liberati A, Tetzlaff J, Altman DG, The PRISMA Group. Preferred reporting items for systematic reviews and meta-analyses: the PRISMA statement. PLoS Med 2009;6(7):e1000097.

25. Vandenbroucke JP, Von Elm E, Altman DG, Gøtzsche PC, Mulrow $\mathrm{CD}$, Pocock SJ, et al. Strengthening the Reporting of Observational Studies in Epidemiology (STROBE): explanation and elaboration. PLoS Med 2007;4(10):e297.

26. Khdour M, Hawwa A, Kidney J, Smyth B, McElnay J. Potential risk factors for medication non-adherence in patients with chronic obstructive pulmonary disease (COPD). Eur J Clin Pharmacol 2012;68 (10):1365-1373.

27. Koehorst-Ter Huurne K, Kort S, van der Palen J, van Beurden W, Movig K, van der Valk P, Brusse-Keizer M. Quality of life and adherence to inhaled corticosteroids and tiotropium in COPD are related. COPD 2016;11:1679-1688.

28. Fischer W, Brandstetter S, Brandl M, Finger T, Böhmer MM, Pfeifer M, Apfelbacher C. Specific, but not general beliefs about medicines are associated with medication adherence in patients with COPD, but not asthma: cohort study in a population of people with chronic pulmonary disease. J Psychosom Res 2018; 107:46-52.

29. Price D, Keininger DL, Viswanad B, Gasser M, Walda S, Gutzwiller FS. Factors associated with appropriate inhaler use in patients with COPD - lessons from the REAL survey. Int J Chron Obstruct Pulmon Dis 2018;13:695-702.

30. Duarte-de-Araújo A, Teixeira P, Hespanhol V, Correia-de-Sousa J. COPD: understanding patients' adherence to inhaled medications. Int J Chron Obstruct Pulmon Dis 2018;13:2767-2773.

31. Humenberger M, Horner A, Labek A, Kaiser B, Frechinger R, Brock $\mathrm{C}$, et al. Adherence to inhaled therapy and its impact on chronic obstructive pulmonary disease (COPD). BMC Pulm Med 2018;18(1): 163. 


\section{MedicAtion AdHERENCE IN COPD}

32. Mueller S, Wilke T, Bechtel B, Punekar YS, Mitzner K, Virchow JC. Non-persistence and non-adherence to long-acting COPD medication therapy: a retrospective cohort study based on a large German claims dataset. Respir Med 2017;122:1-11.

33. Sulaiman I, Cushen B, Greene G, Seheult J, Seow D, Rawat F, et al. Objective assessment of adherence to inhalers by patients with chronic obstructive pulmonary disease. Am J Respir Crit Care Med 2017;195 (10): 1333-1343.

34. Mehuys E, Boussery K, Adriaens E, Bortel LV, Bolle LD, Tongelen IV, et al. COPD management in primary care: an observational, community pharmacy-based study. Ann Pharmacother 2010;44(2):257266.

35. Laforest L, Licaj I, Devouassoux G, Hartwig S, Marvalin S, Van Ganse E. Factors associated with early adherence to tiotropium in chronic obstructive pulmonary disease. Chron Respir Dis 2013;10 (1):11-18.

36. Laforest L, Denis F, van Ganse E, Ritleng C, Saussier C, Passante N, et al. Correlates of adherence to respiratory drugs in COPD patients. Prim Care Respir J 2010;19(2): 148-154.

37. Chrystyn H, Small M, Milligan G, Higgins V, Gil EG, Estruch J. Impact of patients' satisfaction with their inhalers on treatment compliance and health status in COPD. Respir Med 2014;108(2):358-365.

38. Ingebrigtsen TS, Marott JL, Nordestgaard BG, Lange P, Hallas J, Dahl $\mathrm{M}$, et al. Low use and adherence to maintenance medication in chronic obstructive pulmonary disease in the general population. J Gen Intern Med 2015;30(1):51-59.

39. Koehorst-ter Huurne K, Movig K, van der Valk P, van der Palen J, Brusse-Keizer M. Differences in adherence to common inhaled medications in COPD. COPD 2015;12(6):643-648.

40. Tøttenborg SS, Lange P, Johnsen SP, Nielsen H, Ingebrigtsen TS, Thomsen RW. Socioeconomic inequalities in adherence to inhaled maintenance medications and clinical prognosis of COPD. Respir Med 2016;119:160-167.

41. Vetrano DL, Bianchini E, Onder G, Cricelli I, Cricelli C, Bernabei R, et al. Poor adherence to chronic obstructive pulmonary disease medications in primary care: role of age, disease burden and polypharmacy. Geriatr Gerontol Int 2017;17(12):2500-2506.

42. Yu AP, Guérin A, Ponce de Leon D, Ramakrishnan K, Wu EQ, Mocarski M, et al. Therapy persistence and adherence in patients with chronic obstructive pulmonary disease: multiple versus single longacting maintenance inhalers. J Med Econ 2011;14(4):486-496.

43. Cecere LM, Slatore CG, Uman JE, Evans LE, Udris EM, Bryson CL, et al. Adherence to long-acting inhaled therapies among patients with chronic obstructive pulmonary disease (COPD). COPD 2012;9(3): 251-258.

44. Huetsch JC, Uman JE, Udris EM, Au DH. Predictors of adherence to inhaled medications among veterans with COPD. J Gen Intern Med 2012;27(11):1506-1512.

45. Ismaila A, Corriveau D, Vaillancourt J, Parsons D, Dalal A, Su Z, et al. Impact of adherence to treatment with tiotropium and fluticasone propionate/salmeterol in chronic obstructive pulmonary diseases patients. Curr Med Res Opin 2014;30(7):1427-1436.

46. Qian J, Simoni-Wastila L, Rattinger GB, Zuckerman IH, Lehmann S, Wei YJJ, et al. Association between depression and maintenance medication adherence among Medicare beneficiaries with chronic obstructive pulmonary disease. Int J Geriatr Psychiatry 2014;29(1):49-57.

47. Krauskopf K, Federman AD, Kale MS, Sigel KM, Martynenko M, O'Connor R, et al. Chronic obstructive pulmonary disease illness and medication beliefs are associated with medication adherence. COPD 2015;12(2):151-164.

48. Albrecht JS, Yujin P, Hur P, Ting-Ying H, Harris I, Netzer G, et al. Adherence to maintenance medications among older adults with chronic obstructive pulmonary disease. The role of depression. Ann Am Thorac Soc 2016;13(9):1497-1504.
49. Amin AN, Ganapathy V, Roughley A, Small M. Confidence in correct inhaler technique and its association with treatment adherence and health status among US patients with chronic obstructive pulmonary disease. Patient Prefer Adherence 2017;11:1205-1212.

50. Bogart M, Stanford RH, Laliberté F, Germain G, Wu J, Duh MS. Medication adherence and persistence in chronic obstructive pulmonary disease patients receiving triple therapy in a USA commercially insured population. Int J Chron Obstruct Pulmon Dis 2019;14:343352.

51. Wei YJ, Simoni-Wastila L, Albrecht JS, Huang TY, Moyo P, Khokhar $\mathrm{B}$, et al. The association of antidepressant treatment with COPD maintenance medication use and adherence in a comorbid medicare population: a longitudinal cohort study. Int J Geriatr Psychiatry 2018;33(2): e212-e220.

52. Takemura M, Mitsui K, Itotani R, Ishitoko M, Suzuki S, Matsumoto $\mathrm{M}$, et al. Relationships between repeated instruction on inhalation therapy, medication adherence, and health status in chronic obstructive pulmonary disease. Int J Chron Obstruct Pulmon Dis 2011;6(1):97104.

53. Shrestha R, Pant A, Shakya Shrestha S, Shrestha B, Gurung RB, Karmacharya BM. A cross-sectional study of medication adherence pattern and factors affecting the adherence in chronic obstructive pulmonary disease. Kathmandu Univ Med J (KUMJ) 2015;13(49):64-70.

54. Kokturk N, Polatli M, Oguzulgen IK, Saleemi S, Al Ghobain M, Khan J, et al. Adherence to COPD treatment in Turkey and Saudi Arabia: results of the ADCARE study. COPD 2018;13:1377-1388.

55. Ngo CQ, Phan DM, Vu GV, Dao PN, Phan PT, Chu HT, et al. Inhaler technique and adherence to inhaled medications among patients with acute exacerbation of chronic obstructive pulmonary disease in Vietnam. Int J Environ Res Public Health 2019;16(2):185.

56. Turan $\mathrm{O}$, Yemez B, Itil $\mathrm{O}$. The effects of anxiety and depression symptoms on treatment adherence in COPD patients. Prim Health Care Res Dev 2014;15(3):244-251.

57. Tanaka K, Kamiishi N, Miyata J, Kabata H, Masaki K, OguraTomomatsu H, et al. Determinants of long-term persistence with tiotropium bromide for chronic obstructive pulmonary disease. COPD 2015;12(3):233-239.

58. Jarab AS, Mukattash TL. Exploring variables associated with medication non-adherence in patients with COPD. Int J Clin Pharm 2019;41 (5):1202-1209.

59. George J, Kong DC, Thoman R, Stewart K. Factors associated with medication nonadherence in patients with COPD. Chest 2005;128 (5):3198-3204.

60. Sriram KB, Percival M. Suboptimal inhaler medication adherence and incorrect technique are common among chronic obstructive pulmonary disease patients. Chron Respir Dis 2016;13(1):13-22.

61. Galal IH, Mohammad YM, Nada AA, Mohran YE. Medication adherence and treatment satisfaction in some Egyptian patients with chronic obstructive pulmonary disease and bronchial asthma. Egypt J Bronchol 2018;12(1):33-40.

62. Restrepo RD, Alvarez MT, Wittnebel LD, Sorenson H, Wettstein R, Vines DL, et al. Medication adherence issues in patients treated for COPD. Int J Chron Obstruct Pulmon Dis 2008;3(3):371-384.

63. Morgan SG, Lee A. Cost-related non-adherence to prescribed medicines among older adults: a cross-sectional analysis of a survey in 11 developed countries. BMJ Open 2017;7(1):e014287.

64. Macquart de Terline D, Kane A, Kramoh KE, Ali Toure I, Mipinda JB, Diop IB, et al. Factors associated with poor adherence to medication among hypertensive patients in twelve low and middle income Sub-Saharan countries. PloS One 2019;14(7):e0219266.

65. Briesacher BA, Gurwitz JH, Soumerai SB. Patients at-risk for costrelated medication nonadherence: a review of the literature. J Gen Intern Med 2007;22(6):864-871. 


\section{MedicAtion AdHERENCE IN COPD}

66. Horne R, Weinman J. Patients' beliefs about prescribed medicines and their role in adherence to treatment in chronic physical illness. J Psychosom Res 1999;47(6):555-567.

67. Baiardini I, Braido F, Giardini A, Majani G, Cacciola C, Rogaku A, et al. Adherence to treatment: assessment of an unmet need in asthma. J Investig Allergol Clin Immunol 2006;16(4):218-223.

68. Buston KM, Wood SF. Non-compliance amongst adolescents with asthma: listening to what they tell us about self-management. Fam Pract 2000;17(2):134-138.

69. Ponieman D, Wisnivesky JP, Leventhal H, Musumeci-Szabó TJ, Halm EA. Impact of positive and negative beliefs about inhaled corticosteroids on adherence in inner-city asthmatic patients. Ann Allergy Asthma Immunol 2009; 103(1):38-42.

70. Dompeling E, Van Grunsven PM, Van Schayck CP, Folgering H, Molema J, Van Weel C. Treatment with inhaled steroids in asthma and chronic bronchitis: long-term compliance and inhaler technique. Fam Pract 1992;9(2):161-166

71. Benson J, Britten N. Patients' decisions about whether or not to take antihypertensive drugs: qualitative study. BMJ 2002;325(7369):873.

72. Brandstetter S, Finger T, Fischer W, Brandl M, Böhmer M, Pfeifer M, et al. Differences in medication adherence are associated with beliefs about medicines in asthma and COPD. Clin Transl Allergy 2017;7:39.

73. Bjermer L. The importance of continuity in inhaler device choice for asthma and chronic obstructive pulmonary disease. Respiration 2014;88(4):346-352.

74. Van der Palen J, Klein J, Van Herwaarden C, Zielhuis G, Seydel E. Multiple inhalers confuse asthma patients. Eur Respir J 1999;14 (5):1034-1037.

75. Foden J, Hand CH. Does use of a corticosteroid/long-acting beta-agonist combination inhaler increase adherence to inhaled corticosteroids? Prim Care Respir J 2008;17(4):246-247.

76. Ofori-Asenso R, Ilomäki J, Tacey M, Zomer E, Curtis AJ, Bell JS, et al. Patterns of statin use and long-term adherence and persistence among older adults with diabetes. J Diabetes 2018;10(9):699-707.

77. Huber MB, Wacker ME, Vogelmeier CF, Leidl R. Comorbid influences on generic health-related quality of life in COPD: a systematic review. PLoS One 2015;10(7):e0132670.

78. Schane RE, Woodruff PG, Dinno A, Covinsky KE, Walter LC. Prevalence and risk factors for depressive symptoms in persons with chronic obstructive pulmonary disease. J Gen Intern Med 2008;23 (11):1757-1762
79. Light RW, Merrill EJ, Despars JA, Gordon GH, Mutalipassi LR. Prevalence of depression and anxiety in patients with COPD: relationship to functional capacity. Chest 1985;87(1):35-38.

80. Bourbeau J, Bartlett S. Patient adherence in COPD. Thorax 2008;63 (9):831-838

81. Bosley C, Corden Z, Rees P, Cochrane G. Psychological factors associated with use of home nebulized therapy for COPD. Eur Respir J 1996;9(11):2346-2350

82. Hayes-Watson C, Nuss H, Tseng TS, Parada N, Yu Q, Celestin M, et al. Self-management practices of smokers with asthma and/or chronic obstructive pulmonary disease: a cross-sectional survey. COPD Res Pract 2017;3:3.

83. Darbà J, Ramírez G, Sicras A, Francoli P, Torvinen S, Rosa S-DL. R. The importance of inhaler devices: the choice of inhaler device may lead to suboptimal adherence in COPD patients. Int J Chron Obstruct Pulmon Dis 2015; 10:2335-2345.

84. Barnes PJ. Corticosteroid resistance in patients with asthma and chronic obstructive pulmonary disease. J Allergy Clin Immunol 2013; 131(3):636-645.

85. Ciechanowski PS, Katon WJ, Russo JE, Walker EA. The patient-provider relationship: attachment theory and adherence to treatment in diabetes. Am J Psychiatry 2001;158(1):29-35.

86. Hyre AD, Krousel-Wood MA, Muntner P, Kawasaki L, DeSalvo KB. Prevalence and predictors of poor antihypertensive medication adherence in an urban health clinic setting. J Clin Hypertens (Greenwich) 2007;9(3):179-186.

87. Zimmerman E, Woolf SH, Virginia Commonwealth University. Understanding the relationship between education and health. NAM Perspectives 2014;4

88. van Beerendonk I, Mesters I, Mudde AN, Tan T. Assessment of the inhalation technique in outpatients with asthma or chronic obstructive pulmonary disease using a metered-dose inhaler or dry powder device. J Asthma 1998;35(3):273-279.

89. Lareau SC, Hodder R. Teaching inhaler use in chronic obstructive pulmonary disease patients. J Am Acad Nurse Pract 2012;24(2):113-120.

90. Molimard M, Colthorpe P. Inhaler devices for chronic obstructive pulmonary disease: insights from patients and healthcare practitioners. J Aerosol Med Pulm Drug Deliv 2015;28(3):219-228.

91. World Health Organization. Fact sheet on COPD. Available at: http:// www.who.int/en/news-room/fact-sheets/detail/chronic-obstructivepulmonary-disease-(copd). Accessed Nov 11, 2018. 